\title{
Children's Health Insurance
}

\section{Determinants of Children's Participation in California's Medicaid and SCHIP Programs}

\author{
Jennifer Kincheloe, Janice Frates, and E. Richard Brown
}

Objective. To develop a comprehensive predictive model of eligible children's enrollment in California's Medicaid (Medi-Cal [MC]) and State Children's Health Insurance Program (SCHIP; Healthy Families [HF]) programs.

Data Sources/Study Setting. 2001 California Health Interview Survey data, data on outstationed eligibility workers (OEWs), and administrative data from state agencies and local health insurance expansion programs for fiscal year 2000-2001.

Study Design. The study examined the effects of multiple family-level factors and contextual county-level factors on children's enrollment in Medicaid and SCHIP.

Data Collection/Extraction Methods. Simple logistical regression analyses were conducted with sampling weights. Hierarchical logistic regressions were run to control for clustering.

Principal Findings. Participation in MC and HF programs is determined by a combination of family-level predisposing, perceived need, and enabling/disabling factors, and county-level enabling/disabling factors. The strongest predictors of MC enrollment were family-level immigration status, ethnicity, and income, and the presence of a countylevel "expansion program"; and the county-level ratio of OEWs to eligible children. Important $\mathrm{HF}$ enrollment predictors included family-level ethnicity, age, number of hours a parent worked, and urban residence; and county-level population size and outreach and media expenditure.

Conclusions. MC and HF outreach/enrollment efforts should target poorer and immigrant families (especially Latinos), older children, and children living in larger and urban counties. To reach uninsured eligible children, it is important to further simplify the application process and fund selected outreach efforts. Local health insurance expansion programs increase children's enrollment in MC.

Key Words. Medicaid, SCHIP, eligibility, outreach, enrollment

In California, and throughout the nation, many low-income children are eligible for but not enrolled in Medicaid or the State Children's Health Insurance Program (SCHIP) and thus remain uninsured. How to best identify, enroll, and retain eligible children in these public programs is a persistent 
policy challenge, to which states have responded by conducting many different types of outreach and educational campaigns. This study tests the hypothesis that participation in California's Medi-Cal (Medicaid/MC) and Healthy Families (SCHIP/HF) programs is determined by a combination of family predisposing, perceived need, and enabling/disabling factors, and county enabling/disabling factors. We analyze the relative contribution of family and county characteristics to enrollment status. The findings suggest ways to more effectively target outreach efforts to specific populations.

\section{BACKGROUND AND LITERATURE REVIEW}

Increasing health insurance coverage for low-income children has been a national health policy focus for the past two decades. Medicaid expansions beginning in the late 1980s and the Personal Responsibility and Work Opportunity Reconciliation Act (PRWORA) of 1996 extended eligibility to millions of children by increasing family income limits and by separating the health insurance benefit from the cash aid programs. The SCHIP, enacted in 1997, further expanded coverage to children with incomes above the Medicaid income eligibility limit but without access to employer sponsored coverage. These programs have made a significant difference: In 1987, 30.8 percent of low-income children were uninsured; by 2002, this figure was 18.6 percent (Selden, Hudson, and Banthin 2004).

As a result of these eligibility expansions, the great majority of uninsured low income children are eligible for Medicaid or SCHIP, up to 95 percent depending on the income level used (Selden, Banthin, and Cohen 1998; Broaddus and Ku 2000). However, early enrollment in SCHIP fell far short of expectations; in the first two program years, states spent just 24 percent of the federal funding available (Kenney, Ulman, and Weil 2000). By 2002, 79 percent of children under 18 eligible for Medicaid were enrolled, and 60 percent of SCHIP eligible children were enrolled. Except for undocumented children, uninsurance for low-income children is now more a problem of participation than of eligibility (Selden Hudson, and Banthin 2004).

Address correspondence to Jennifer Kincheloe, Ph.D., Research Scientist, UCLA Center for Health Policy Research, 10960 Wilshire Blvd, Suite 1550, Los Angeles, CA 90024. Janice Frates, Ph.D., Professor, is with the Health Care Administration Program, California State University Long Beach, Long Beach, CA. E. Richard Brown, Ph.D., is Director of the UCLA Center for Health Policy Research, and Professor at the UCLA School of Public Health, Los Angeles, CA. 
Several studies, using focus groups and population-based survey data, have sought to explain why many eligible families do not enroll their children in the Medicaid and SCHIP programs. Unawareness of or confusion about program eligibility were commonly cited as significant barriers to participation; many working parents assumed they and their children were ineligible (Feld, Matlock, and Sandman 1998; Perry et al. 2000; Kenney and Haley 2001; Brown et al. 2002; Kenney, Haley, and Tebay 2003). Another obstacle was lengthy and cumbersome application and enrollment procedures (MediCal Policy Institute 2000; Perry et al. 2000; Ross and Cox 2000; Kenney and Haley 2001). The stigma of publicly sponsored health insurance was an issue for some families (Perry et al. 2000; Cunningham 2001).

A number of parent and family characteristics have been identified as influencing enrollment in public health insurance programs. Children more likely to be enrolled in Medicaid had parents who were younger, less educated, poorer, single, immigrants, had more children or a family member in fair or poor health (Davidoff and Garrett 2001). While nonwhites in California reported more problems navigating the enrollment system than whites (MediCal Policy Institute 2000), another national study found that black or Hispanic ethnicity was positively associated with Medicaid enrollment, although Hispanic ethnicity was also a predictor of uninsurance (Davidoff and Garrett 2001). Language barriers impeded access for parents with limited English proficiency (Medi-Cal Policy Institute 2000; Perry et al. 2000), while bilingual application assisters increased new Medicaid enrollment for California Hispanics and Asians (Aizer 2003).

The effect of immigration status involves several factors. Children of immigrants are more likely to be eligible for Medicaid, because immigrant families tend to be larger and poorer than those of native-born residents. However, eligibility expansions mainly increased coverage for native-born children. Eligible immigrants face higher "transaction costs" of applying, including concerns about the use of benefits adversely affecting a future citizenship application. Also, immigrant parents aware that Medicaid covers acute care costs retrospectively may forego enrolling eligible children (Zimmerman and Fix 1998; Currie 2000; Kaushal and Kaestner 2005).

Low-income children with health problems are more likely to be enrolled in Medicaid or SCHIP, and some parents of healthy children do not perceive a need for insurance (Kenney and Haley 2001; Blumberg, O'Connor, and Kenney 2005). Many parents lack knowledge about Medicaid and SCHIP; others do not recognize the benefits of health insurance coverage (Brown et al. 2002). 
SCHIP programs based on private insurance models typically include several features that can impede access. "Lockouts" (imposing a minimum period of uninsurance for children with access to employer coverage) and cost sharing are two such features (Halfon, Inkelas, and Newacheck 1999), although other qualitative research suggests that families prefer to pay something toward the cost of coverage and care (Lewin Group 1998). Studies from other states indicate that parents are more likely to enroll their children in health insurance programs for which they are also eligible, and that allowing an entire family to apply at once increases the probability that children will be covered (Ku and Broaddus 2000).

\section{CALIFORNIA'S MEDICAID AND SCHIP PROGRAMS}

California has more uninsured residents than any other state; over 1.1 million children were uninsured for all or part of the year in 2003, 11.2 percent of all California children, based on data from the California Health Interview Survey (CHIS). Approximately 55 percent of children who were uninsured at the time of the CHIS interview were eligible for MC or HFs (Brown et al. 2005).

California implemented its HFs program as a separate state program from MC. HF employs a private insurance model, and differs from MC in several important aspects: (1) the HF program requires monthly premiums and co-pays, while all care under MC is free; (2) parents of $\mathrm{HF}$ children are not eligible for this program, but parents of MC eligible children may be eligible for MC; (3) HF "locks out" children with employer-sponsored coverage within three months of applying for HF coverage, but there is no waiting period for children applying for MC; and (4) HF applications are processed by a centralized, state-level agency, creating statewide uniformity, while county welfare departments handle much of the MC eligibility determination and enrollment, creating room for county-level variation.

California developed a joint application for MC and $\mathrm{HF}$, but the first version of this document was 27 pages. Program officials and advocacy group representatives labored to reduce it to four pages and to create a single point of entry for processing it. With philanthropic funding, state officials also developed an online application that is now available statewide.

HF was launched in 1998 with a statewide advertising campaign. After 2000, the state redirected funds to conduct more targeted, coordinated and community-based outreach for MC and HF. The HF administering agency funded a training and certification program for application assisters (typically 
bilingual, bicultural individuals with strong community ties) and, until 2003, paid health insurance brokers and application assisters fees of $\$ 50$ and $\$ 25$ for new and renewing children, respectively. Since 2003, the state has greatly reduced outreach funding and also eliminated enrollment payments for almost 2 years, restoring them in 2005.

Beginning in 2000, a number of California counties have developed local expansion programs to enable all children in low- to moderate-income families in a particular county to obtain subsidized health insurance at minimal cost. These local initiatives expand coverage to two groups of children ineligible for MC or HF: those with family incomes slightly above the HF limit of 250 percent of poverty (most upper income limits go up to 300, but one is 400 percent), and undocumented immigrant children. These local initiative products mirror HF, with nominal copayments and a heavily subsidized premium. They also incorporate a vigorous outreach effort to enroll all uninsured low- to moderate-income children in the county in whatever program for which they qualify, involve extensive public-private collaboration and provide strong leadership to integrated outreach and enrollment efforts. When this study took place just three expansion programs were operational. As of March 2006, coalitions in 18 counties had implemented expansion programs with a total enrollment of about 85,000 children; another 12 are planning similar initiatives (Institute for Health Policy Solutions 2006). Two private organizations, California Kids Healthcare Foundation and the Kaiser Permanente health plan, have offered subsidized coverage to a limited number of children statewide since 1992 and 1997, respectively.

\section{CONCEPTUAL FRAMEWORK}

Figure 1 is a graphic representation of how family-level demographic factors interact with county-level contextual factors to produce an enrollment outcome. This model draws upon work by Andersen (1995) measuring access to medical care and Donebedian (1980) on medical care quality to create a framework for explaining children's enrollment in MC and HF.

\section{Family-Level Factors}

Parental characteristics are important determinants of a child's enrollment status. These predisposing factors include parental age, gender, race/ethnicity, level of acculturation, educational level, and income. Predisposing factors influence parental attitudes about insurance and government programs, and 
Figure 1: Framework for Explaining Children's Enrollment in the Medi-Cal and Healthy Families Programs.

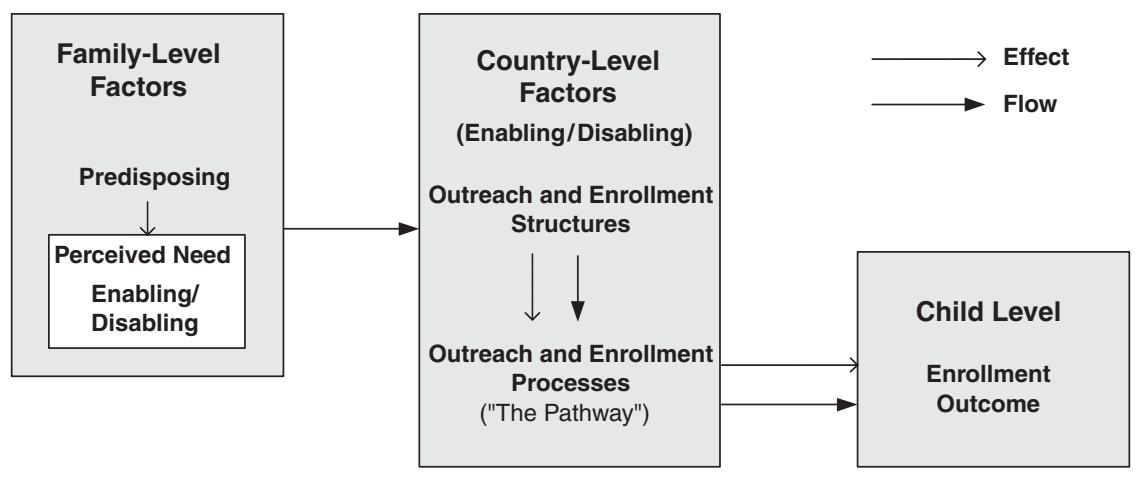

thus shape a parent's "perceived need" to obtain health insurance coverage for a child. Perceived need factors in our model include the child's age, gender, and health status, and whether the child has a regular source of medical care.

Enabling/disabling factors are those that would facilitate or frustrate a parent's attempts to enroll a child in MC or HF. These include: the amount of free time a parent has to complete the application process; the number of children in the family; marital status; a parent's mental well-being; whether they have social support or a social network; whether they live in a rural or urban area; English proficiency; and the availability and convenience of transportation.

\section{County-Level Structure and Process Factors}

In Figure 1, solid arrows flow from family-level factors to county-level factors, from structures to processes, and from county-level factors to the child-level enrollment outcome. These arrows indicate that parents must go through the structures and processes (enabling/disabling factors) in their county to learn about the programs and enroll their eligible child. Characteristics of county outreach and enrollment structures and processes can also be understood as community enabling/disabling factors that facilitate or frustrate a family's enrollment (Andersen 1995).

Structure can be defined as the programs' stable characteristics, and the physical and organizational settings in which outreach and enrollment efforts take place. It includes human, physical and financial resources; the number, distribution and qualifications of professional staff; and program evaluation and quality improvement systems (Donebedian 1980). Structures affect the 
quality of processes and increase or decrease the probability that a quality interaction will occur during the outreach and enrollment processes. In Figure 1, a dotted arrow runs between structures and processes to indicate this effect.

$\mathrm{MC}$ enrollment and MC and $\mathrm{HF}$ outreach in California are conducted at the county level, with much variation among counties. These variations include: the design and funding of media campaigns; the number, type, scope, and funding levels of programs engaged in $\mathrm{MC}$ and $\mathrm{HF}$ outreach and enrollment; the location, hours, and policies of enrollment sites; the quality and training of outreach and enrollment staff; and the availability of county expansion or private subsidy programs. As federal and state-level factors apply uniformly across California, there is no variability of federal and state-level factors within the MC and $\mathrm{HF}$ programs across counties.

Process is defined as activities between outreach/enrollment workers and the parents of eligible children, shown as steps along the enrollment pathway in our model. "Best practices" are the standards against which process activities are measured (Donebedian 1980).

\section{Enrollment Outcome}

A child's enrollment status is an indirect measure of both the quality and quantity of outreach and enrollment processes for the $\mathrm{MC}$ and $\mathrm{HF}$ programs. High rates of participation by eligible children would likely reflect an effective or high quality outreach and enrollment process; low participation rates could reflect a lower quantity or quality of outreach and enrollment programs. However, the effect of enrollment and outreach processes have to be distinguished from other factors that can affect enrollment, such as the demand for health insurance (perceived need).

\section{Methods}

\section{Data Sources}

This study used cross sectional data from CHIS 2001 (2002), a random digit dialed telephone survey of more than 56,000 households drawn from every county in California and conducted in English, Spanish, Chinese (Mandarin and Cantonese dialects), Vietnamese, Korean, and Khmer (Cambodian). Its sample includes over 18,000 children under age 18 whose parent was interviewed about their health insurance coverage. The survey identified 2,573 children age 0-17 either enrolled in $\mathrm{MC}$ or eligible for $\mathrm{MC}$ but uninsured and 1,431 children either enrolled in HF or eligible and uninsured. CHIS's large 
sample size provides more precise estimates of the number of children eligible for MC and $\mathrm{HF}$ than national surveys, and allows for estimation of differences across counties and detailed analyses for certain ethnic minorities.

Using CHIS data to study enrollment by eligible children in both programs has some limitations. First, CHIS may exclude vulnerable populations without access to telephones, although the sample weights partially compensate for lack of telephone coverage. Second, all populations survey estimates of MC enrollment differ somewhat from state administrative data for the same period of time (Blumberg and Cynamon 1999). CHIS questions on MC and $\mathrm{HF}$ enrollment were developed especially to reduce underreporting. CHIS estimates for MC are closer to state enrollment counts than other surveys, such as the Current Population Survey (Brown et al. 2002), and CHIS estimates for HF match state administrative enrollment numbers. Lastly, we studied the association between parental characteristics and children's enrollment in MC and HF. CHIS interviews only one parent, one adolescent, and one child in each household. Thus, age, ethnicity and hours worked per week were not available for the second parent (where present) introducing omitted variable bias. ${ }^{1}$ Also, because families enroll all their children in MC and/or HF at the same time, the health status of siblings is a potentially important predictor for which we did not have data, and another potential source of omitted variable bias. This study also used administrative data from the California State Department of Health Services (DHS) and the Managed Risk Medical Insurance Board (MRMIB) which administer MC and HF, respectively. These data are from fiscal year (FY) 2000-2001 and included county-level data on: the number of applications processed; the number of children deemed ineligible due to incomplete applications; the amount of money disbursed for outreach in FY 1999-2000 and FY 2000-2001. These disbursements include monies to train certified application assistants and to fund media outreach; grants to community-based organizations and schools for outreach and enrollment support; and outreach for MC 1931b, a program that enables working families to have full scope $\mathrm{MC}$ coverage when they are not receiving cash aid.

We did not include private outreach expenditures in this analysis because of the enormity of the task of gathering the data from the plethora of private foundations in California that may or may not have funded local outreach efforts. The data that we did obtain were incomplete, and not sufficiently specific to separate money used for outreach from money used for other purposes. We estimate that three major California foundations (The California Endowment, California HealthCare Foundation, and Packard Foundation) funded about $\$ 17,000,000$ in outreach activities for MC and $\mathrm{HF}$ 
during the study period, compared with $\$ 63,496,438$ provided by the state. Without exception, these funds went to counties that received outreach grants from the state, perhaps because counties that applied for state grants were also more likely to apply for private funding. Because of omitted variable bias, this analysis may slightly overestimate the magnitude of the effect of public outreach expenditures, because some of the effect may be attributed to the receipt of private outreach funds. However, funds from private foundations represent only about 20 percent of total outreach expenditures identified in this study.

Lastly, this study incorporated data from a statewide survey conducted by the MC Policy Institute in March 1999 (the most recent data available) that measured the sites in each county with outstationed eligibility workers (OEWs), whether these sites had evening and weekend hours and whether they allowed walk-in appointments (Blackburn and Happoldt 1999).

\section{Measures}

The unit of analysis in this study is the eligible child. Data on the characteristics of eligible children were linked with their parents' characteristics and those of the county of residence. Individual-level variables for parents included age, ethnicity, immigration status, English language proficiency, years residing in the United States, marital status, hours worked per week, mental well-being and education. Child factors included age, gender, health status, and enrollment status. Family-level factors included income per member, languages spoken in the home, number of children, rural or urban location, and county of residence.

County-level variables included outreach dollars received from the state per eligible child (excluding state media dollars); state media campaign dollars spent per eligible child; whether a county-based expansion program or a private program (Kaiser Permanente Cares for Kids [KPCK] or California Kids [CK]) was operating in to cover low-income children ineligible for public programs; the number of outstationed MC eligibility workers per eligible child; whether outstations offered walk-in, evening or weekend appointments; and county size. County-level process measures included the number of applications processed in FY 2000-2001 per 1,000 eligible children, and the percent of incomplete applications in FY 2000-2001.

\section{Analytical Model}

Two different types of analyses were conducted to accommodate this study's unique dataset. The first analysis was a simple logistic regression that applied sampling weights to the data to make them representative of all MC and $\mathrm{HF}$ 
eligible children in the county and state (CHIS 2002). Weights incorporated the probability that each child in the sample would be selected and corrected biases due to nonresponse and the exclusion of households without telephones.

A simple logistic regression model was developed using Stata to estimate the effects of individual-, family-, and county-level factors on uninsured children's enrollment in MC and in $\mathrm{HF}$, controlling for the clustering of observations within counties An adjusted Wald's test determined the joint significance of blocks of variables representing domains from the conceptual model. An unweighted hierarchical logistic regression model was independently developed to control for clustering at both the family and county level using MLWin. This software is suited to study county-level variance with multiple counties and small sample sizes within some counties. Using the same criteria, the models developed somewhat differently.

The simple logistic regression model makes estimates based on the concept of a finite population, weighted to reflect the actual population of California as it is distributed between counties. The hierarchical model makes estimates based on the assumption that the population being modeled is infinite. The counties included in this analysis can be considered a sample from a hypothetical infinite population of counties.

An enrollment status variable was constructed based on parents' responses to CHIS (2002) questions on their child's insurance status and eligibility for the MC and HF programs at the time of the interview. About 100 contributing variables were used to construct the final eligibility variable, reflecting the complexity of both programs' eligibility rules. Children automatically enrolled in MC due to their family's participation in cash aid programs were excluded from the samples because there is no variation in enrollment outcome in this population.

\section{RESULTS}

Tables 1 and 2 compare results from the simple logistic regressions and the hierarchical models. Because these two models generate estimates based on different assumptions, the similar results from both analytic models reinforce the robustness of the study conclusions: The results from a three-level model, which controlled for clustering at the family level, were identical to the results of the two-level model, which did not control for this clustering, suggesting that clustering at the family level did not bias the analysis. However, the survey 
Table 1: Comparing Models: A Simple Logistic Regression Model and a Multilevel Model to Predict Children's Enrollment in Medi-Cal

\begin{tabular}{|c|c|c|c|c|}
\hline \multirow{2}{*}{$\begin{array}{l}\text { Medi-Cal Sample } \\
\text { Dependent Variable: Enrollment Status (Yes/No) }\end{array}$} & \multicolumn{2}{|c|}{$\begin{array}{l}\text { Simple Logistic } \\
\text { Regression Model }\end{array}$} & \multicolumn{2}{|c|}{$\begin{array}{l}\text { Two-Level Logistic } \\
\text { Regression Model }\end{array}$} \\
\hline & $O R$ & P-Value & $O R$ & Significant* \\
\hline
\end{tabular}

Family-level predisposing factors

Immigration status (reference: citizen parents)

One parent citizen, one parent green card holder

One parent citizen, one parent noncitizen with no green card

Both parents green card holders or single green card holder parent

One parent green card holder, one parent noncitizen with no green card

Both parents noncitizen no green card or single

$\begin{array}{rrrr}0.64 & .17 & 0.84 & \text { No } \\ 0.49 & .08 & 0.86 & \text { No } \\ 0.51 & .02 & 0.57 & \text { Yes } \\ 0.26 & <.01 & 0.49 & \text { Yes } \\ 0.67 & .16 & 0.84 & \text { No }\end{array}$
noncitizen parent with no green card

Language of parent (reference: English only)

Other language spoken at home/good English proficiency

Other language spoken at home/poor or no

English proficiency

Ethnicity (reference: white)

African American (non-Latino)

Asian/Pacific Islander (non-Latino)

Latino

American Indian/Alaskan Native (non-Latino)

Other (non-Latino)

Borderline

Household income per capita (Reference:

$>\$ 20,000$ )

$\$ 10,000$ or less per person

$\$ 10,001$ to $\$ 20,000$ per person

Family-level perceived need factors

Age of child (reference: birth to age two)

Age 3-11

Family-level enabling/disabling factors

Urban residence

$1.55 \quad$ Yes

County-level enabling/disabling factors

Structural measures

County size (reference: large $>100,000$ )

Less than 10,000 children (small)

$$
\text { 10,001-100,000 children (medium) }
$$

Other expansion program

Number of outstations per 1,000 eligible children

Media money per eligible child ${ }^{\dagger}$
$2.97 \quad 0.08$
3.84

$3.84<.01$

1.62

Yes

2.83

.06

.04

$0.47 \quad$ Yes

$0.97 \quad$ Yes 
Table 1: Continued

\begin{tabular}{|c|c|c|c|c|}
\hline \multirow{2}{*}{$\begin{array}{l}\text { Medi-Cal Sample } \\
\text { Dependent Variable: Enrollment Status (Yes/No) }\end{array}$} & \multicolumn{2}{|c|}{$\begin{array}{l}\text { Simple Logistic } \\
\text { Regression Model }\end{array}$} & \multicolumn{2}{|c|}{$\begin{array}{c}\text { Two-Level Logistic } \\
\text { Regression Model }\end{array}$} \\
\hline & OR & $P$-Value & $O R$ & Significant" \\
\hline $\begin{array}{l}\text { Outreach money per eligible child (excluding } \\
\text { media) }\end{array}$ & 1.06 & .08 & & \\
\hline $\begin{array}{l}\text { Interaction term-outreach money per eligible } \\
\text { child } \times \text { small county }\end{array}$ & 0.93 & .04 & & \\
\hline $\begin{array}{l}\text { Interaction term-outreach money per eligible } \\
\text { child } \times \text { medium county }\end{array}$ & 0.93 & .06 & & \\
\hline \multicolumn{5}{|l|}{ Process measures } \\
\hline $\begin{array}{l}\text { Applications processed per eligible child in } \\
\text { county }\end{array}$ & 0.99 & .36 & & \\
\hline
\end{tabular}

*An estimate is deemed significant if it is greater than twice the standard error of the estimate.

${ }^{\dagger}$ The state distributed media money by Designated Market Area (DMA) and not by county. A DMA may consist of one county or a grouping of several adjacent counties. Counties that were not assigned to any DMA were grouped together. To estimate the amount of media money spent per eligible child in each county, I used the amount of media money spent per eligible child in the DMA.

weights used in the simple logistic regression did prove to be important. The results obtained from the hierarchical model mirror results from an unweighted simple regression model. We conclude that the simple regression model was better than the hierarchical model because it corrected for biases introduced by sampling, nonresponse, and households without telephones, and because the specific issues addressed by the hierarchical model proved to be less important: The variation among counties was explained by county-level variables, and family-level clustering did not affect the results.

Tested as a block, family-level predisposing factors are significant predictors of enrollment for both the MC and the HF programs $(p \leq .05)$. Neither recent arrival in the United States nor language is associated with enrollment in either program sample. Immigration status was a strong predictor of enrollment in the MC model $(p \leq .05)$, but not in the HF model. Children of noncitizen parents were less likely to be enrolled in MC than children with two citizen parents. However, it was not the children of undocumented parents (or "noncitizens without green cards") who had the lowest program participation, but rather the children of parents with permanent legal residency. Ethnicity was a strong predictor of enrollment in both the MC and the HF models $(p \leq .05)$. Whites and Latinos were much less likely to enroll in MC than African Americans, Asians, American Indians, and Alaskan Natives (AIANs). Among HF eligible children, Asians and African Americans had higher odds 
Table 2: Comparing Models: A Simple Logistic Regression Model and a Multilevel Model to predict Children's Enrollment in Healthy Families

\begin{tabular}{|c|c|c|c|c|}
\hline \multirow{2}{*}{$\begin{array}{l}\text { Healthy Families Sample } \\
\text { Dependent Variable: Enrollment Status (Yes/No) }\end{array}$} & \multicolumn{2}{|c|}{$\begin{array}{l}\text { Simple Logistic } \\
\text { Regression Model }\end{array}$} & \multicolumn{2}{|c|}{$\begin{array}{l}\text { Two-Level Logistic } \\
\text { Regression Model }\end{array}$} \\
\hline & OR & $P$-Value & $O R$ & Significant \\
\hline \multicolumn{5}{|l|}{ Family-level predisposing factors } \\
\hline \multicolumn{5}{|l|}{ Immigration status (reference: citizen parents) } \\
\hline One parent citizen, one parent green card holder & 0.62 & .09 & 0.75 & No \\
\hline $\begin{array}{l}\text { One parent citizen, one parent noncitizen with no } \\
\text { green card }\end{array}$ & 1.97 & .21 & 1.58 & No \\
\hline $\begin{array}{l}\text { Both parents green card holders or single green } \\
\text { card holder parent }\end{array}$ & 0.82 & .47 & 0.98 & No \\
\hline $\begin{array}{l}\text { One parent green card holder one parent } \\
\text { noncitizen with no green card }\end{array}$ & 0.58 & .21 & 0.91 & No \\
\hline $\begin{array}{l}\text { Both parents noncitizen no green card or single } \\
\text { noncitizen parent with no green card }\end{array}$ & 1.02 & .96 & 1.08 & No \\
\hline \multicolumn{5}{|l|}{ Language of parent (reference: English only) } \\
\hline $\begin{array}{l}\text { Other language spoken at home, speaks good } \\
\text { English }\end{array}$ & 1.36 & .30 & & \\
\hline $\begin{array}{l}\text { Other language spoken at home, speaks poor } \\
\text { or no English }\end{array}$ & 1.50 & .23 & & \\
\hline \multicolumn{5}{|l|}{ Ethnicity (reference: non-Latino white) } \\
\hline African American (non-Latino) & 3.00 & .02 & 1.01 & No \\
\hline Asian/Pacific Islander (non-Latino) & 2.45 & .02 & 2.45 & Yes \\
\hline Latino & 0.92 & .78 & 1.28 & No \\
\hline American Indian/Alaskan Native (non-Latino) & 0.39 & .08 & 0.52 & No \\
\hline Other (non-Latino) & 0.75 & .52 & 1.03 & No \\
\hline \multicolumn{5}{|l|}{ Household income per capita (reference: $>\$ 20,000$ ) } \\
\hline$\$ 10,000$ or less per person & & & 0.92 & No \\
\hline$\$ 10,001-\$ 20,000$ per person & & & 1.80 & Yes \\
\hline \multicolumn{5}{|l|}{ Family-level perceived need factors } \\
\hline \multicolumn{5}{|l|}{ Age of child (reference: birth to age two) } \\
\hline Age $3-11$ & 0.63 & .10 & 0.79 & No \\
\hline Age $12-17$ & 0.40 & $<.01$ & 0.54 & Yes \\
\hline \multicolumn{5}{|l|}{ Family-level enabling/disabling factors } \\
\hline \multicolumn{5}{|l|}{ Hours worked per week (reference: 0 hours) } \\
\hline Worked some, less than 20 hours & 0.72 & .45 & & \\
\hline Worked between 21 and 40 hours & 0.81 & .32 & & \\
\hline Worked more than 40 hours per week & 0.61 & .05 & & \\
\hline Number of children in the family & & & 1.15 & Yes \\
\hline Urban residence & 0.61 & .03 & 0.69 & Yes \\
\hline \multicolumn{5}{|l|}{ County-level enabling/disabling factors } \\
\hline \multicolumn{5}{|l|}{ Structural measures } \\
\hline \multicolumn{5}{|l|}{ County size (reference: large $>100,000$ children) } \\
\hline Less than 10,000 children (small) & 7.74 & .01 & & \\
\hline $10,001-100,000$ children (medium) & 2.09 & .15 & & \\
\hline
\end{tabular}


Table 2: Continued

\begin{tabular}{|c|c|c|c|c|}
\hline \multirow{2}{*}{$\begin{array}{l}\text { Healthy Families Sample } \\
\text { Dependent Variable: Enrollment Status (Yes/No) }\end{array}$} & \multicolumn{2}{|c|}{$\begin{array}{l}\text { Simple Logistic } \\
\text { Regression Model }\end{array}$} & \multicolumn{2}{|c|}{$\begin{array}{l}\text { Two-Level Logistic } \\
\text { Regression Model }\end{array}$} \\
\hline & OR & $P$-Value & OR & Significant \\
\hline Outstations per 1,000 eligible children & 0.94 & .91 & & \\
\hline County expansion program & 1.17 & .76 & & \\
\hline $\begin{array}{l}\text { At least one expansion program (KPCFK, } \mathrm{CK} \text {, or } \\
\text { a county expansion program) }\end{array}$ & & & 1.56 & Yes \\
\hline Outreach money per eligible child & 1.07 & .05 & & \\
\hline Outreach money per eligible child/small county & 0.89 & .01 & & \\
\hline $\begin{array}{l}\text { Outreach money per eligible child/medium } \\
\text { county }\end{array}$ & 0.94 & .16 & & \\
\hline Media money spent per eligible child in the DMA & 0.89 & .01 & 0.96 & Yes \\
\hline Process measures & & & & \\
\hline $\begin{array}{l}\text { Applications per } 1,000 \text { eligible children in the } \\
\text { county }\end{array}$ & 1.02 & .06 & & \\
\hline
\end{tabular}

*An estimate is deemed significant if it is greater than twice the standard error of the estimate.

of being enrolled compared with whites, and Latinos had similar odds. AIANs had only 40 percent the odds of whites, a reversal of what was found in the MC program $(p=.07)$.

When tested as a block, perceived need factors were significant predictors of enrollment in both programs $(p \leq .05)$. A child's age was a strong predictor of enrollment in the HF program. Health status, a potentially endogenous variable, was positively associated with enrollment status in the MC model, but not in the HF model. Healthy children had 50 percent better odds of being enrolled in $\mathrm{MC}$ compared with those reported as being in fair or poor health $(p \leq .05)$.

Taken together, family-level enabling/disabling factors were significant predictors of enrollment in both the MC and HF programs, although individual variables were significant only in the HF models. Family-level enabling/disabling factors measured in this study include hours worked per week, emotional well-being, the number of children in the household, marital status, and rural versus urban residence. While children with working parents had lower odds of enrollment compared to those whose parents did not work, only those whose parents worked more than 40 hours per week had significantly lower odds $(p=.05)$. Children living in urban settings had over 40 percent lower odds of enrollment in HF than children living in nonurban settings $(p \leq .05)$. 
When tested as a group, county-level factors were significant predictors of MC enrollment $(p \leq .05)$, but were not significant for the HF program. However, individual variables were significant for both programs. Media money spent per eligible child in the Designated Market Area (DMA) was a significant predictor of $\mathrm{HF}$ enrollment; however, the direction of the effect was contrary to expectations. For every additional dollar per eligible child in the DMA that was spent on media, the odds of enrollment actually decreased among the HF sample by nine percentage points $(p \leq .05)$. The amount of money spent on outreach (excluding the media campaign) was associated with greater enrollment in both the MC and HF programs. The odds of being enrolled in $\mathrm{MC}$ increased by 6 percentage points for each additional dollar spent on outreach per eligible child in the county $(p=.08)$, and for HF eligible children the odds increased by seven percentage points $(p \leq .05)$.

Children who lived in counties with a county-sponsored expansion program had almost three times the odds of being enrolled in MC compared with children from counties without such a program in place $(p=.06)$. The private KPCK and CK programs were not associated with increased MC enrollment. For HF, county-sponsored expansion programs, KPCK and CK were all positively associated with enrollment, but these results were not statistically significant. The application rate was associated with enrollment in the HF program only, with an increase of two percentage points in the odds of enrollment for every additional application per 1,000 eligible children in the county $(p=.06)$. This variable specifically applies to joint applications received for the HF program and was only a proxy measure of the number of applications received by the MC program. The number of outstations per 1,000 eligible children in the county was negatively associated with enrollment, and the presence of evening, weekend, or walk-in hours at outstations was not associated with enrollment in either program.

\section{DISCUSSION}

The theoretical framework for predicting enrollment in the MC and HF programs set forth in this study is a useful paradigm for studying program enrollment. Most of the variation in enrollment status occurs at the family level, but both family- and county-level factors are important predictors of enrollment in both the $\mathrm{MC}$ and the $\mathrm{HF}$ programs.

While study findings do not establish causality, they suggest relationships that may be explained in context. For example, the lack of association 
between language and enrollment in the regression model suggests that state efforts to target linguistic minorities with outreach, including the translation of enrollment materials into 10 different languages, have been working. Children of undocumented immigrants and green card holders are less likely to enroll, likely reflecting concerns about the use of benefits prejudicing a future citizenship application (Zimmerman and Fix 1998). Lower participation by AIANs in the HF program when this group's MC participation was high may be partially explained by the failure of California to implement a federal policy to exempt AIANs from paying HF premiums (Satter et al. 2002).

Parents who work full time were less likely to enroll their child compared with nonworking parents, perhaps reflecting that working parents have less time to enroll their children. Children from large counties were less likely to enroll, suggesting that large county bureaucracies may be less responsive and connected to the communities they serve compared with smaller agencies, and thus less able to foster program enrollment.

Dollars spent on the statewide media campaign had a negative association with $\mathrm{HF}$ enrollment, although the media campaign may have generated greater awareness of the HF program. Initially, the HF program featured a burdensome application process, and parents experienced problems with enrollment. These experiences may have fostered negative reports in the community about the program and discouraged participation. Increased product awareness can interact with negative information, resulting in greater dissatisfaction compared with areas with lower product awareness (Gaskell et al. 1999). This same relationship was not seen with MC, which was already well known.

OEWs were associated with lower enrollment. Outstations are resource intensive and OEWs process fewer applications than their counterparts stationed in welfare offices (Blackburn and Happoldt 1999). Also, many safety net hospitals use OEWs to offset uncompensated care, channeling high-cost uninsured patients to the worker to apply for emergency MC coverage. These patients are less likely to be children (Vilander 2004). Outstations are partially funded by MC and $\mathrm{HF}$ outreach subventions from the state to counties, and take funding away from other outreach efforts that may be more effective with children. Further research is needed to establish whether certain types of outstations are more effective for reaching children than others. For example, hospital outstations may reach adults but few children. However, school-based outstations may be effective with children and warrant the high resource expenditure associated with outstationing.

Residency in a county with a county-sponsored expansion programs was strongly associated with enrollment in MC but not $\mathrm{HF}$, although local 
initiatives aim to increase enrollment in both programs. The positive association with $\mathrm{MC}$ enrollment may be due to the vigorous implementation of outreach and enrollment activities when local public-private coalitions and their leaders become invested in achieving strong results. The reason that a similar association was not seen for HFs may be due to the difficulties that local initiatives report in following up with HF applications because these applications are processed by state contractors who observe strict confidentiality. In contrast, local initiatives collaborate with county agencies that determine MC eligibility (Alameda County Health Services Agency 2002). Research published subsequent to this study found that the Santa Clara County Children's Health Initiative led to large enrollment gains in both MC and HF (Trenton and Orzol 2004). Further comparative research examining changes in children's MC and HF program enrollment over time in counties with and without local initiatives is needed to assess the broader impact of these initiatives.

\section{CONCLUSION AND POLICY IMPLICATIONS}

Progress has been made in enrolling eligible children in public programs, and further efforts are needed to broaden coverage. Although the design of this study does not identify causal relationships, findings from it suggest that to better target eligible but uninsured children we can: (1) target linguistic minorities and immigrants, especially Latinos; (2) reassure immigrants that use of $\mathrm{MC}$ or HF is not considered being a public charge; (3) communicate culturally relevant messages about the benefits of having health insurance; (4) further simplify enrollment; (5) fund outreach by community-based organizations and agencies; and (6) expand eligibility to include more children or support county-based expansion programs that do so.

\section{ACKNOWLEDGMENTS}

This research was supported by funds from the California Program on Access to Care (CPAC), California Policy Research Center, University of California. The views and opinions expressed do not necessarily represent those of the Regents of the University of California, CPAC, its advisory board or any state or county executive agency represented thereon.

The authors appreciate the guidance provided by Gerald Kominski, Jeff Luck, and Tom Belin on the dissertation that was the basis for this article. 
Disclosures: Not applicable.

Disclaimers: Not applicable except as noted above in acknowledgment.

\section{NOTE}

1. We suspect that age and ethnicity may be somewhat correlated between parents, limiting the impact of this omission. We suspect that the relationship between hours worked per week and enrollment was diluted by this omission for the following reasons. Families that receive cash-aid were excluded from the analysis, and thus most families have at least one worker, and many have two workers. Thus, in instances where the parent interviewed worked full time or more, it is possible that there is in that family (1) a second working parent or (2) a parent who did not work or worked few hours. However, in instances where the parent interviewed worked few or no hours, it is much less likely that the second parent does not work because they are not receiving welfare.

\section{REFERENCES}

Aizer, A. 2003. "Low Take-Up in Medicaid: Does Outreach Matter and for Whom?" American Economic Review 93 (2): 238-41.

Alameda County Health Care Services Agency. 2002. Report of the SCHIP Project Results. Berkeley, CA: Alameda County Health Care Services and Social Services Agencies.

Andersen, R. 1995. "Revisiting the Behavioral Model and Access to Medical Care: Does It Matter?" Journal of Health and Social Behavior 36: 1-10.

Blackburn, J., and I. A. Happoldt. 1999. Medi-Cal Outstationing in California: Findings from a Statewide Survey. Oakland, CA: Medi-Cal Policy Institute, California HealthCare Foundation.

Blumberg, S. J., K. S. O’Connor, and G. Kenney. 2005. “Unworried Parents of Well Children: A Look at Uninsured Children Who Reportedly Do Not Need Health Insurance." Pediatrics 116 (2): 345-51.

Blumberg, S. J., and M. L. Cynamon. 1999. "Misreporting Medicaid Enrollment: Results of Three Studies Linking Telephone Surveys to State Administrative Records." In 7th Conference on Health Survey Research Methods, Williamsburg VA, edited by M. L. Cynamon and R. A. Kulka. Available at http://www.cdc.gov/ nchs/data/conf/conf07.pdf [accessed 19 July 2006]. pp. 189-96.

Broaddus, M., and L. Ku. 2000. Nearly 95 Percent of Low Income Uninsured Children Now Are Eligible for Medicaid or SCHIP: Measures Need to Increase Enrollment among Eligible but Uninsured Children" [accessed on November 17, 2001]. Available at http://www.cbpp.org/12-6-00schip.pdf 
Brown, E. R., S. A. Lavarreda, T. Rice, J. R. Kincheloe, and M. S. Gatchell. 2005. The State of Health Insurance in California: Findings from the 2003 California Health Interview Survey. Los Angeles: UCLA Center for Health Policy Research.

Brown, E. R., N. Ponce, T. Rice, and S. A. Lavarreda. 2002. The State of Health Insurance in California: Findings from the 2001 California Health Interview Survey. Los Angeles: UCLA Center for Health Policy Research.

California Health Interview Survey. 2002. CHIS 2001 Methodology Series: Report 5-Weighting and Variance Estimation. Los Angeles: UCLA Center for Health Policy Research.

Cunningham, P. J. 2001. "Targeting Communities with High Rates of Uninsured Children." Health Affairs (Millwood) (web exclusive): W20-9.

Currie, J. 2000. Do Immigrant Children Use Medicaid Differently? Santa Monica, CA: RAND.

Davidoff, A. J., and B. Garrett. 2001. "Determinants of Public and Private Insurance Enrollment among Medicaid-Eligible Children.” Medical Care 39 (6): 523-35.

Donebedian, A. 1980. The Definition of Quality and Approaches to Its Assessment. Ann Arbor, MI: Health Administration Press.

Feld, P., C. Matlock, and D. Sandman. 1998. Insuring the Children of New York City's LowIncome Families. Focus Group Findings on Barriers to Enrollment in Medicaid and Child Health Plus. New York: The Commonwealth Fund.

Gaskell, G., M. W. Bauer, J. Durant, and N. Allum. 1999. "World Apart? The Reception of Genetically Modified Foods in Europe and the U.S." Science 285: 384-7.

Halfon, N., M. Inkelas, and P. W. Newacheck. 1999. "Enrollment in the State Child Health Insurance Program: A Conceptual Framework for Evaluation and Continuous Quality Improvement." Milbank Quarterly 77 (2): 181-204.

Institute for Health Policy Solutions. 2006. "Local Coverage Solutions" [accessed April 30, 2006]. Available at http://www.ihps-ca.org/localcovsol/index.html

Kaushal, N., and R. Kaestner. 2005. "Welfare Reform and Health Insurance of Immigrants." Health Services Research 40: 697-721.

Kenney, G., and J. Haley. 2001. Why Aren't More Uninsured Children Enrolled in Medicaid or SCHIP? Washington, DC: The Urban Institute.

Kenney, G. M., J. Haley, and A. Tebay. 2003. Familiarity with Medicaid and SCHIP Programs Grows and Interest in Enrolling Children Is High. Washington, DC: The Urban Institute.

Kenney, G. M., F. C. Ullman, and A. Weil. 2000. Three Years into SCHIP: What States Are and Are Not Spending. Washington, DC: The Urban Institute.

$\mathrm{Ku}, \mathrm{L}$. , and M. Broaddus. 2000. The Importance of Family-Based Insurance Expansions: New Research Findings about State Health Reforms. Washington, DC: Center on Budget and Policy Priorities.

Lewin Group. 1998. Children's Health Insurance Expansions: State Experiences in Developing Benefit Packages and Cost-Sharing Arrangements. Fairfax, VA: Lewin Group.

Medi-Cal Policy Institute. 2000. Speaking Out: What Beneficiaries Say about the MediCal Program. Oakland, CA: Medi-Cal Policy Institute, California HealthCare Foundation. 
Perry, M., S. Kannel, R. B. Valdez, and C. Chang. 2000. Medicaid and Children: Overcoming Barriers to Enrollment: Findings from a National Survey. Washington, DC: The Kaiser Commission on Medicaid and the Uninsured.

Ross, D. C., and L. Cox. 2000. Making It Simple: Medicaid for Children and CHIP Income Eligibility Guidelines and Enrollment Procedures. Washington, DC: Kaiser Commission on Medicaid and the Uninsured.

Satter, D. E., S. Wallace, T. Le, and S. Zubiate. 2002. Improving Health Insurance Coverage for American Indian Children and Families under Healthy Families (SCHIP). Los Angeles: UCLA Center for Health Policy Research.

Selden, T. M., J. S. Banthin, and J. W. Cohen. 1998. "Medicaid's Problem Children: Eligible but Not Enrolled." Health Affairs (Millwood) 17 (3): 192-200.

Selden, T. M., J. L. Hudson, and J. S. Banthin. 2004. "Tracking Changes in Eligibility and Coverage among Children." Health Affairs (Millwood) 23 (5): 39-50.

Trenton, C., and S. Orzol. 2004. The Impact of the Children's Initiative (CHI) of Santa Clara County on Medi-Cal and Healthy Families Enrollment. Princeton, NJ: Mathematica Policy Research.

Vilander, K. 2004 “Southern California Hospital Association.” Personal communication.

Zimmerman, W., and M. Fix. 1998. Declining Immigrant Applications for Medi-Cal and Welfare Benefits in Los Angeles County. Washington, DC: The Urban Institute. 